\title{
The Relationship between Breastfeeding and Parental Socioeconomic Status: an analysis of the Korea National Health and Nutrition Examination Survey ( 2013 2017 )
}

Jusuk Lee

Samsung Changwon Hospital

Taehong Kim ( $\square$ md3728@pednet.co.kr)

Pusan National University Yangsan Hospital https://orcid.org/0000-0003-2411-2309

Research article

Keywords: Breastfeeding, Parental, Socioeconomic status, Korea

Posted Date: May 8th, 2020

DOI: https://doi.org/10.21203/rs.3.rs-25616/v1

License: (1) (1) This work is licensed under a Creative Commons Attribution 4.0 International License. Read Full License 


\section{Abstract}

Background: The importance of breastfeeding is well known. One of important factors affecting breastfeeding is socioeconomic status. We investigated the relationship between socioeconomic status and breastfeeding to promote future breastfeeding projects.

Methods: Data were collected from the 2013 - 2017 Korea National Health and Nutrition Examination Survey (KNHANES). We evaluated the demographic information and parents' socioeconomic status of 814 children, aged $12 \sim 60$ months.

Results: Of the 814 children, 743 (92.2\%) were breastfed. In univariate analysis, parents' age and education level were related to breastfeeding $(P<0.05)$. In logistic regression analysis, mothers' education level ( $\leq 13$ years: odd ratio[OR], $8.57 ; 95 \%$ confidence interval [Cl], 2.73-26.87), mothers' income level (third quartile: OR, 2.94; $95 \% \mathrm{Cl}, 1.2-7.23)$, fathers' age (20s: OR, 0.3; $95 \% \mathrm{Cl}, 0.09-0.98)$, fathers' education level (1012years: OR 4.85; $95 \% \mathrm{Cl}, 1.4-16.76$ and 13years: OR, 18.55; 95\% Cl, 5.23-65.81), fathers' income (third quartile: OR, 2.72; 95\% Cl 1.02-7.22) were associated with breastfeeding $(P<0.05)$.

Conclusion: Higher parental income and education level and fathers' age were positively associated with breastfeeding in Korea. The establishment of future breastfeeding projects should be considered target parents in Korea and other countries.

\section{Introduction}

The benefits of breastfeeding are well known. Breastfeeding reduces respiratory infections, gastrointestinal tract infections, necrotizing enterocolitis, sudden infant death syndrome, otitis media in children younger than 2years of age, allergic disorders (asthma, atopic dermatitis), diabetes, obesity, acute leukemia, hypertension, and neurodevelopmental disorder. ${ }^{1,2}$ In addition, breastfeeding benefits mothers' health, including reducing the risk of breast cancer, ovarian cancer, type 2 diabetes. ${ }^{2-4}$ The World Health Organization (WHO) and American Academy of Pediatrics (AAP) recommend exclusive breastfeeding for the first six months, followed by continued breastfeeding for 1year or longer as complementary foods are introduced. 4,5

Globally, $43 \%$ of infants aged younger than six months were exclusively breastfed in 2016, an increase from $36 \%$ in 2005 . The prevalence of exclusive breastfeeding was highest in Southern Asia (59 \%) and Eastern Africa (57\%). It is much lower in Latin America and the Caribbean (33\%), Eastern Asia (28\%), Western Africa (25\%), and Western Asia (21\%). ${ }^{6}$

In 2006-2012, only an estimated 25\% of infants in the WHO European Region were exclusively breastfed for the first 6 months. ${ }^{7}$ After birth, between $56 \%$ and $98 \%$ of infants in European countries (Ireland, 56\%; the Netherlands, $80 \%$; Italy, 86\%; Sweden, 94\%; Germany, 97\%; and Norway, $98 \%$ ) were breastfed. At 6 months age, the following breastfeeding rates were reported: Italy (38\%), the Netherlands (51\%), Germany $(57 \%)$, Sweden (61\%), Norway (71\%). Although early initiation of breastfeeding is very high in some countries, exclusive breastfeeding rates drop rapidly between 4 and 6 months of age and are very low at 6 months: Denmark,13\%; Germany, 19\%; Norway, 17\%; Sweden, 14\%; the Netherlands, $39 \% .^{8}$

Among infants born in 2015 in the United States, 4 out of 5 (83.2\%) were breastfed at birth, over half (57.6\%) were breastfed at 6 months-old, and over one-third (35.9\%) were breastfed at 12 months-old. However, despite the recommendation to breastfeed exclusively for about the first 6 months, less than $50 \%$ of infants were exclusively breastfed in the first 3 months, and $24.9 \%$ were exclusively breastfed in the first 6 months. ${ }^{9}$

Between 1985 and 1995, the global rates of exclusive breastfeeding increased by $2.4 \%$ per year on average (increasing from $14 \%$ to $38 \%$ over 10 years). ${ }^{10}$ The Global Breastfeeding Collective, led by UNICEF and the WHO, set a target to increase the global rate of exclusive breastfeeding in the first 6 months of life: at least $50 \%$ by 2025 and at least $70 \%$ by $2030 .{ }^{10,11}$

In Korea, the rates of breastfeeding at 6months of age increased to $60.8 \%$ in 2010 and 62.3\% in 2013; however, it decreased to $55.6 \%$ in 2016 . The Korean Ministry of Health and Welfare's Fourth National Health Plan aims to increase to $66.8 \%$ by $2020 .{ }^{12}$

Although the socioeconomic factors associated with breastfeeding have been broadly reported, scant studies have examined these variables in Korea. Therefore, we explored the relationship between socioeconomic factors and breastfeeding in Korea using data from the Korean National Health and Nutrition Examination Survey(KNHANES). Information from this study will help increase breastfeeding practice and the overall breastfeeding rate.

\section{Methods}


This study was conducted using the raw data from the KNHANES of the sixth (2013 2015) and the seventh term (2016 2017). The KNHANES is a statutory survey on people's health behavior, prevalence of chronic diseases, and food and nutrition practices. KNHANES was conducted in a three-year period from the first (1998) to the third period (2005), and has since been reorganized into a year-round survey system, and has been conducted annually from the fourth term (2007-2009) to the present day. KNHANES consisted of a cross-sectional survey composed of a health interview survey and a health examination survey, and a nutrition survey. All survey protocols were approved by the Korea Centers for Disease Control \& Prevention (KCDC) Institutional Review Board. Written informed consent was obtained from all participants before the survey commencement.

In this study, we included 1,534 children over 12 months under 60 months out of 31,098 participants in the sixth and seventh terms. Of these, we excluded 718 participants who were no information of breastfeeding $(n=365)$, did not provide socio-economic data( $n=41)$, and were raised by single parents $(n=312)$. The remaining 814 participants were included in the final analysis (Fig.1)

\section{Study design}

This study employed a cross-sectional design. All data are available from the KNHANES database (http://knhanes.cdc.go.kr/knhanes). We categorized data into two groups (non-breastfed, breastfed). These surveys included questions regarding sex, age, residence, employment status, education level, incomes. Education level was divided into 3 categories: $\leq 9 y e a r s, 10 \sim 12$ years, $\geq 13 y e a r s$. Income was classified into quartiles to determine income level (1: low, 2: middle low, 3: middle high, 4: high),

\section{Data analysis}

Statistical Package for the Social Sciences (SPSS) complex sample procedures were employed since KNHANES data were collected through a representative, stratified, and clustered sampling method. Participants' characteristics are presented as a percentage and a $95 \%$ confidence interval. Differences between the breastfeeding and non-breastfeeding groups are reported using chi-square test. We conducted a logistic regression analysis to identify the relationships between factors and breastfeeding. We first adjusted for maternal education level and income level (model 1) and then for the variables in model 1 plus paternal age, education level and income level. Statistical analysis was conducted using SPSS version 21.0 (SPSS Inc. Chicago, IL, US). For all analyses, p-values were two-tailed, and a P value $<0.05$ was considered significant.

\section{Results}

\section{Participants' characteristics}

As shown on Table 1, this study included 814 children. Male comprised $51.55 \%$. Mean birth weight was $3.21 \mathrm{~kg}$ and a majority of the participants' age were over 3years (35.81\%). Most enrolled participants lived in urban areas (83.37\%). 92.18\% of participants were breastfed. Majority of mothers' age was 30s (77.01\%), education level was 10 12years (33.98\%), income level was 2(29.76\%), non-working mothers were $65.17 \%$. Majority of father's age was 30s (72.05\%), education level was 10 12years (29.84\%), income level was 1(29.98\%), 2(28.91\%), respectively. $79.91 \%$ of fathers had occupation. 
Table 1

Demographic Characteristics of Participants

\begin{tabular}{|c|c|c|}
\hline & $\mathbf{N}$ & Estimate(95\% Cl) \\
\hline \multicolumn{3}{|l|}{$\operatorname{Sex}(n=814)$} \\
\hline male & 407 & $51.55(47.92-55.17)$ \\
\hline female & 407 & $48.45(44.83-52.08)$ \\
\hline \multicolumn{3}{|l|}{$\operatorname{Age}(n=814)$} \\
\hline 1year & 269 & $32.47(29.45-35.65)$ \\
\hline 2years & 260 & $31.72(28.47-35.16)$ \\
\hline$\geq 3$ years & 285 & $35.81(32.40-39.37)$ \\
\hline Birth weight $(n=814)$ & 814 & $3.21(3.18-3.24)$ \\
\hline \multicolumn{3}{|l|}{ Residence $(n=814)$} \\
\hline Rural & 136 & $16.63(12.35-22.02)$ \\
\hline Urban & 678 & $83.37(77.98-87.65)$ \\
\hline \multicolumn{3}{|l|}{ Breastfeeding( $n=814)$} \\
\hline No & 68 & $7.82(5.83-10.40)$ \\
\hline Yes & 746 & 92.18 (89.60-94.17) \\
\hline \multicolumn{3}{|l|}{ Mother's Information } \\
\hline \multicolumn{3}{|l|}{ Age $(n=814)$} \\
\hline $20 s$ & 115 & 14.09 (11.34-17.38) \\
\hline $30 s$ & 628 & 77.01 (73.19-80.43) \\
\hline$\geq 40 S$ & 71 & $8.89(6.83-11.51)$ \\
\hline \multicolumn{3}{|l|}{ Education(n=764) } \\
\hline$\leq 9$ years & 33 & $4.19(2.72-6.39)$ \\
\hline 10 12years & 229 & $29.79(26.06-33.81)$ \\
\hline$\geq 13$ years & 502 & $66.02(61.90-69.92)$ \\
\hline \multicolumn{3}{|c|}{ Income(quartile)(n=814) } \\
\hline 1 & 214 & $27.15(23.56-31.07)$ \\
\hline 2 & 243 & $29.76(26.15-33.64)$ \\
\hline 3 & 193 & $23.15(19.68-27.03)$ \\
\hline 4 & 164 & 19.94 (16.81-23.49) \\
\hline \multicolumn{3}{|l|}{ Employment $(n=814)$} \\
\hline No & 524 & $65.17(61.03-69.10)$ \\
\hline Yes & 290 & 34.83 (30.90-38.97) \\
\hline \multicolumn{3}{|l|}{ Father's information } \\
\hline \multicolumn{3}{|l|}{ Age $(n=814)$} \\
\hline $20 s$ & 32 & $4.36(2.76-6.83)$ \\
\hline $30 s$ & 590 & $72.05(68.06-75.71)$ \\
\hline$\geq 40 \mathrm{~s}$ & 192 & $23.59(20.08-27.50)$ \\
\hline Education $(n=685)$ & & \\
\hline
\end{tabular}

Page $4 / 13$ 


\begin{tabular}{|lcl|}
\hline$\leq 9$ years & 23 & $3.18(1.80-5.55)$ \\
\hline $10 \sim 12$ years & 189 & $26.66(23.02-30.64)$ \\
\hline$\geq 13$ years & 473 & $70.16(65.97-74.05)$ \\
\hline Income(quartile)(n=814) & & \\
\hline 1 & 240 & $29.98(26.25-33.99)$ \\
\hline 2 & 237 & $28.91(25.22-32.91)$ \\
\hline 3 & 187 & $23.25(19.64-27.29)$ \\
\hline 4 & 150 & $17.87(14.91-21.26)$ \\
\hline Employment $(\mathbf{n = 8 1 4 )}$ & & \\
\hline No & 150 & $20.09(17.10-23.46)$ \\
\hline Yes & 664 & $79.91(76.54-82.90)$ \\
\hline
\end{tabular}

\section{Relationships between breastfeeding and socio-economic factors}

Factors related to breastfeeding were mothers' age $(P=0.04)$ and education level $(P<0.001)$, fathers' age $(P<0.001)$ and education level $(P<$ $0.001)$. In the case of breastfeeding, the parents were in their 30 s (father: $73.81 \%$, mother:78.35\%), and the education level was over $13 y e a r s$ (father; 73.24\%, mother; 68.54\%) (Table 2). 
Table 2

Demographic characteristics according to the presence of breastfeeding

\begin{tabular}{|c|c|c|c|}
\hline & Breastfeeding & & \multirow[t]{2}{*}{ P-value } \\
\hline & Yes & & \\
\hline $\operatorname{Sex}(n=814)$ & & & 0.296 \\
\hline Male & $44.61(31.89-58.08)$ & $52.14(48.33-55.93)$ & \\
\hline Female & $55.39(41.92-68.11)$ & $47.86(44.07-51.67)$ & \\
\hline Age $(n=814)$ & & & 0.595 \\
\hline 1year & $38.60(25.85-53.12)$ & 31.95 (28.93-35.13) & \\
\hline 2years & $30.21(19.40-43.78)$ & $31.85(28.48-35.42)$ & \\
\hline$\geq 3$ years & 31.19 (20.28-44.68) & 36.20 (32.67-39.89) & \\
\hline Birth weight(n=814) & $3.11(2.93-3.29)$ & 3.22 (3.18-3.25) & 0.237 \\
\hline Residence(n=814) & & & 0.285 \\
\hline Rural & $11.54(5.63-22.21)$ & 17.06 (12.52-22.81) & \\
\hline Urban & 88.46 (77.79-94.37) & 82.94 (77.19-87.48) & \\
\hline \multicolumn{4}{|l|}{ Mother's information } \\
\hline Age $(n=814)$ & & & 0.040 \\
\hline $20 \mathrm{~s}$ & $23.66(13.36-38.37)$ & $13.28(10.50-16.66)$ & \\
\hline $30 \mathrm{~s}$ & $61.21(45.81-74.66)$ & 78.35 (74.45-81.80) & \\
\hline$\geq 40 \mathrm{~s}$ & $15.13(6.95-29.84)$ & $8.37(6.33-10.98)$ & \\
\hline Education $(n=764)$ & & & $<0.001$ \\
\hline$\leq 9$ years & $14.94(6.30-31.46)$ & $3.27(2.00-5.30)$ & \\
\hline $10 \sim 12$ years & $48.45(33.56-63.63)$ & $28.20(24.46-32.26)$ & \\
\hline$\geq 13$ years & $36.60(23.52-52.01)$ & 68.54 (64.36-72.43) & \\
\hline Income(quartile)(n=814) & & & 0.120 \\
\hline 1 & $41.03(27.82-55.68)$ & 25.98 (22.37-29.93) & \\
\hline 2 & 30.07 (19.12-43.87) & $29.73(25.96-33.80)$ & \\
\hline 3 & $12.90(6.26-24.71)$ & $24.02(20.32-28.15)$ & \\
\hline 4 & $16.00(6.84-33.07)$ & $20.27(17.08-23.89)$ & \\
\hline Employment $(n=814)$ & & & 0.978 \\
\hline No & $65.36(50.28-77.88)$ & $65.16(60.89-69.20)$ & \\
\hline Yes & $34.64(22.12-49.72)$ & 34.84 (30.80-39.11) & \\
\hline \multicolumn{4}{|l|}{ Father's information } \\
\hline Age $(n=814)$ & & & $<0.001$ \\
\hline $20 \mathrm{~s}$ & $15.99(6.50-34.26)$ & 3.38 (2.09-5.42) & \\
\hline $30 \mathrm{~s}$ & $51.28(35.80-66.52)$ & $73.81(69.75-77.49)$ & \\
\hline$\geq 40 \mathrm{~s}$ & 32.73 (19.74-49.05) & $22.81(19.25-26.83)$ & \\
\hline Education ( $\mathrm{n}=685$ ) & & & $<0.001$ \\
\hline$\leq 9$ years & 17.36 (7.18-36.32) & $1.91(0.96-3.76)$ & \\
\hline 10 12 years & $46.70(31.94-62.06)$ & 24.86 (21.32-28.77) & \\
\hline
\end{tabular}

Page 6/13 


\begin{tabular}{|llll|}
\hline$\geq 13$ years & $35.94(22.81-51.58)$ & $73.24(69.20-76.92)$ & \\
\hline Income(quartile)(n=814) & & & 0.159 \\
\hline 1 & $43.12(29.64-57.71)$ & $28.86(25.06-32.99)$ & \\
\hline 2 & $30.13(19.14-44.01)$ & $28.81(24.98-32.96)$ & \\
3 & $13.24(5.86-27.26)$ & $24.10(20.32-28.32)$ & \\
\hline 4 & $13.50(5.60-29.12)$ & $18.24(15.21-21.71)$ & \\
\hline Employment $(\mathbf{n = 8 1 4 )}$ & & & 0.265 \\
\hline No & $14.35(7.38-26.05)$ & $20.58(17.43-24.12)$ & \\
Yes & $85.65(73.95-92.62)$ & $79.42(75.88-82.57)$ & \\
\hline
\end{tabular}

The multivariate analysis revealed that mothers' education level ( $\leq 13 y e a r s:$ odd ratio[OR], 8.57; 95\% confidence interval [CI], 2.73-26.87), mother's income level (third quartile: OR, 2.94; $95 \% \mathrm{Cl}, 1.2-7.23)$, father's age (20s: OR, 0.3; 95\% Cl, 0.09-0.98), father's education level (1012years: OR 4.85; 95\% Cl, 1.4-16.76, 13 years: OR, 18.55; 95\%, 55\%, 5.81), father's income (3rd quartile: OR, 2.72; 95\% Cl 1.02-7.22) were associated with breastfeeding $(P<0.05)$. Model 1 , after adjustment for maternal education and income level, showed that maternal education level ( $\geq$ 13years: OR 7.92; 95\% Cl 2.53-24.82) was associated with breastfeeding, but income level was not. In model 2, which was adjusted model 1 plus fathers' age, education and income level, fathers' education level ( $\geq 13 y e a r s:$ OR 9.24; 95\% Cl 1.76-48.35) was statistically significant (Table 3) 
Table 3

The association between breastfeeding and socioeconomic factors

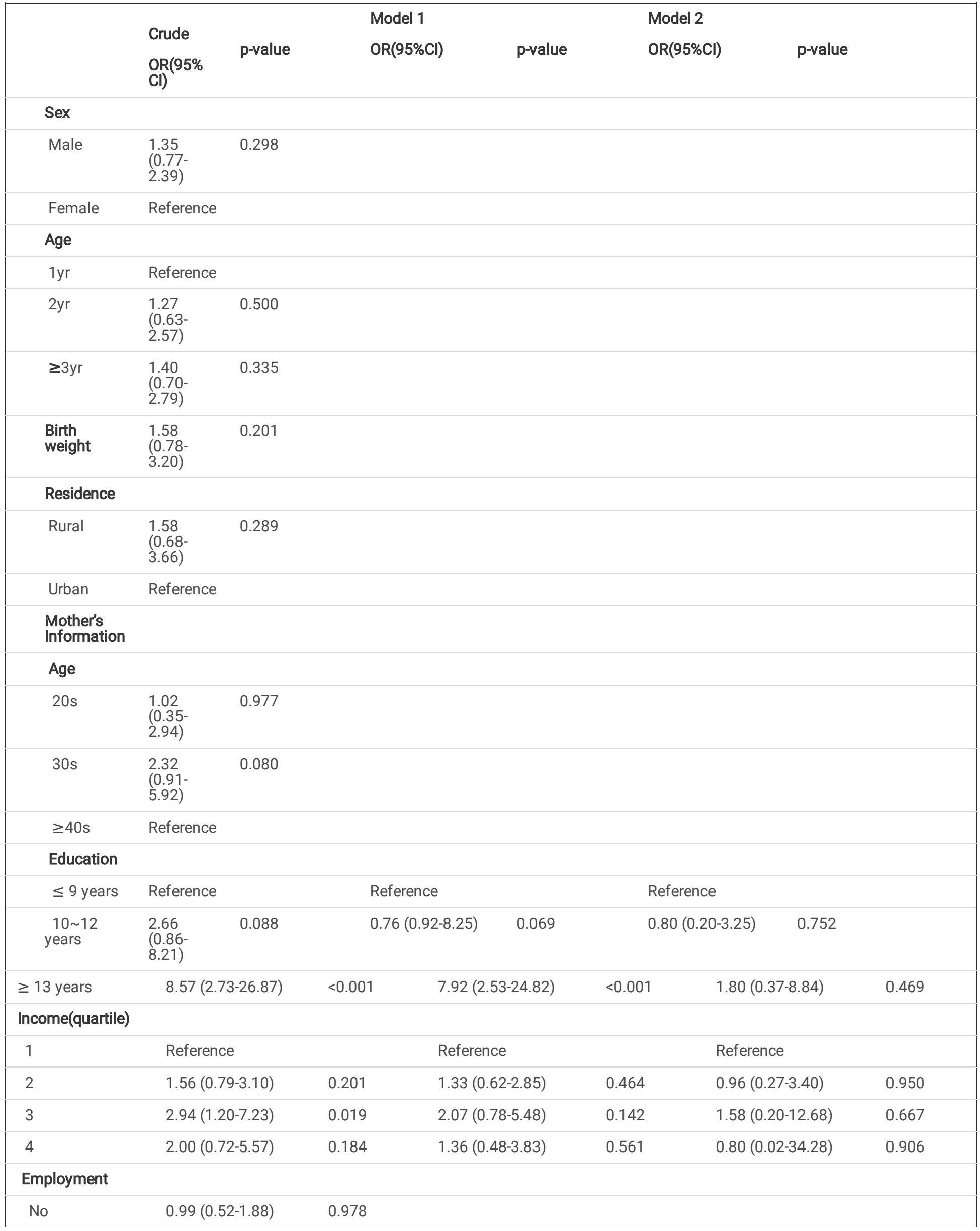




\begin{tabular}{|c|c|c|c|c|}
\hline Yes & Reference & & & \\
\hline \multicolumn{5}{|l|}{$\begin{array}{l}\text { Father's } \\
\text { information }\end{array}$} \\
\hline \multicolumn{5}{|l|}{ Age } \\
\hline $20 \mathrm{~s}$ & $0.30(0.09-0.98)$ & 0.047 & $0.51(0.10-2.55)$ & 0.413 \\
\hline $30 \mathrm{~s}$ & $2.06(1.00-4.28)$ & 0.051 & $2.00(0.90-4.45)$ & 0.089 \\
\hline$\geq 40$ s & Reference & & Reference & \\
\hline \multicolumn{5}{|l|}{ Education } \\
\hline$\leq 9$ years & Reference & & Reference & \\
\hline 10 12 years & $4.85(1.40-16.76)$ & 0.013 & $4.22(0.88-20.19)$ & 0.071 \\
\hline$\geq 13$ years & $18.55(5.23-65.81)$ & $<0.001$ & $9.24(1.76-48.35)$ & 0.009 \\
\hline \multicolumn{5}{|c|}{ Income(quartile) } \\
\hline 1 & Reference & & Reference & \\
\hline 2 & $1.43(0.72-2.82)$ & 0.303 & $0.83(0.23-2.93)$ & 0.769 \\
\hline 3 & $2.72(1.02-7.22)$ & 0.045 & $0.94(0.11-8.30)$ & 0.958 \\
\hline 4 & $2.02(0.72-5.69)$ & 0.184 & $1.17(0.02-62.23)$ & 0.939 \\
\hline \multicolumn{5}{|l|}{ Employment } \\
\hline No & $1.55(0.71-3.35)$ & 0.269 & & \\
\hline Yes & Reference & & & \\
\hline $\begin{array}{l}\text { Model } 1 \text { adjust } \\
\text { Model } 2 \text { adjust } \\
\text { OR; odds ratio, }\end{array}$ & $\begin{array}{l}\text { mother's informatior } \\
\text { model } 1 \text { plus father's } \\
\text { fidence interval }\end{array}$ & $\begin{array}{l}\text { ducation, income ) } \\
\text { formation (age, education and income) }\end{array}$ & & \\
\hline
\end{tabular}

\section{Discussion}

In this study, we revealed that the higher parents' income and education level, the higher the breastfeeding rate; and the younger fathers' age, the lower the breastfeeding rate.

Multiple factors influence breastfeeding. These factors were classified into four groups: demographic, biological, social, and psychological. Demographic factors that affect the breastfeeding rate include race, maternal age, marital status, socioeconomic status, and education level. ${ }^{13}$ In this study, we examined demographic variables that affect breastfeeding.

In this study, most parents were in their 30s and most breastfed their infants; however parental age did not affect breastfeeding. Other studies showed same results. ${ }^{14,15}$ However, several previous reports showed that the older the mothers were more likely to breastfeed than were younger mothers. ${ }^{16-18}$ Oakely et a $\mathrm{I}^{19}$ reported that the younger the mother was, the less likely she was to breastfeed or to stop breastfeeding within 6 weeks. We posit that younger mothers lack knowledge and awareness of breastfeeding.

Banu et $\mathrm{al}^{20}$ stated that the higher the parents' education level, the higher the exclusive breastfeeding rate and longer duration of the exclusive breastfeeding. In this study, parents' education level was also related to breastfeeding. The higher the mother's education level, the higher the breastfeeding rate. In model 1, maternal education level ( $\geq$ 13years) revealed highest breastfeeding rate. It is believed that the higher education level coincides with increased opportunities to access information about the benefits of breastfeeding.In high-income countries, mother's education level is positively associated with higher breastfeeding rate. $16,17,19,21-25$ Even for mothers with a job, breastfeeding rate is estimated to be high, because the higher the level of education, the higher the occupational status, the better the working environment and the better knowing the benefits of breastfeeding. In middle- and low-income countries, the relationship between breastfeeding and mothers' education level varies. Some studies have reported a negative relationship between mothers' education level and the breastfeeding rate owing to quick return to work. ${ }^{18,26}$ Another study showed a higher parental education level was associated with a higher breastfeeding rate and exclusive breastfeeding. ${ }^{27}$ 
We found a positive association between father's education level and breastfeeding. Similar finding has been reported by Flacking et al ${ }^{28}$, who found that the lower the fathers' education level, the lower the breastfeeding rate. We posit that this is related to family income. Because higher education often results in a better income, mothers may not need to work and can focus on parenting. However, other study showed that mothers'-but not fathers'- education level was related breastfeeding, ${ }^{17}$ or that parental education level was not related to breastfeeding. 29,30

Further, in this study, there was no relationship between the mother's income and breastfeeding, however, the higher the income of the father, the higher the breastfeeding rate. This is believed that non-working mother (full-time housewives) composed $65.17 \%$, father is main source of family income. Therefore, the higher the father's income, the greater the mother's devotion to child care, and breastfeeding. Similar results have been reported that the lower the father's income level, the shorter the breastfeeding duration. ${ }^{28}$ This may be related to easy finding a job for mother.

On the contrary, Wallby et $\mathrm{al}^{31}$ reported that higher breastfeeding rate in low-income households. This is believed to be due to the fact that there are no economic condition to choose a different formula besides breast milk and no easy finding a job for mother. Victoria et al ${ }^{4}$ stated that high-income, better-educated women breastfeed more commonly in high-income countries. Due to economic benefits, the lower the household's gross income, the higher the breastfeeding in low-income and middle-income countries. However, in other studies, household income did not affect breastfeeding. ${ }^{15,29}$

Maternal job status is variable that has been associated with breastfeeding. Previous studies ${ }^{14,18,24}$ revealed that full-time houseswives have higher breastfeeding rates than mothers with work and the shorter the time to return to work after childbirth, the shorter the breastfeeding period. It is estimated that they stop breastfeeding because they have less time to care for the child while working. However, we did not find a significant association between breastfeeding and parental job status.

Importantly, our results shed light on some socioeconomic factors associated with breastfeeding; however, this study has some limitations. The utilized data were collected through self - report, and this is a source of recall bias which may have either underestimated or overestimated the relationship between the breastfeeding and socio-economic status. Further, causal relationships cannot be confirmed owing to the crosssectional design of the KNHANES. Also, because it is a survey study, it was not possible to analyze the factors affecting breastfeeding according to the duration of breastfeeding. In addition to the factors used in this study, it is considered that studies on various social factors such as breastfeeding education, use rooming-in, use of postpartum care center, parental leave, and establishment of a breastfeeding room in the workplace are necessary.

\section{Conclusion}

This large population-based study demonstrated that parents' income and education level and fathers' age were positively related to breastfeeding. Our results are especially helpful in establishing evidence-based health policies on breastfeeding in Korea and other countries. To increase the breastfeeding rate and exclusive breastfeeding, further research should explore the reasons why parents stop breastfeeding.

\section{Declaration}

\section{Availability of data and materials}

The datasets generated and /or analyzed during the current study are available from the Korea National Health and Nutrition Examination Survey (http://knhanes.cdc.go.kr/knhanes).

\section{Ethics approval and consent to participate}

All of the participants in the KNHANES were informed that they had been randomly chosen to participate in the survey with the right to participate in the further analyses, and signed an informed consent form. As this was a cross-sectional study that used and analyzed data from KNHANES(http://knhanes.cdc.go.kr/knhanes/), ethical approval was not required.

\section{Consent for publication}

Not applicable 


\section{Competing interests:}

The authors declare that they have no competing interests

\section{Funding}

Not applicable

\section{Authors' contributions}

Conceptualization: THK. Data curation: THK, JSL. Formal analysis: THK, JSL. Investigation: THK, JSL. Methodology: THK, JSL. Writingoriginal draft: THK. Writing-review \& editing: THK, JSL

\section{Acknowledgements}

Not applicable

\section{References}

1. Kramer MS, Kakuma R. Optimal duration of exclusive breastfeeding. Cochrane Database of Systematic Reviews 2012;(8):1-44.

2. Victoria CG, BahI R, Barros AJ, Franca GV, Horton S, Kraevec J, et al. Breastfeeding in the 21st century: epidemiology, mechanisms, and lifelong effect. Lancet 2016;387(10017): 475-90.

3. Chowdhury R, Sinha B, Sankar MJ, Taneja S, Bhandari N, Rollins N, et al. Breastfeeding and maternal health outcomes: a systematic review and meta-analysis. Acta Paediatrica 2015;104(467):96-113.

4. Section on Breastfeeding. Breastfeeding and the use of human milk. Pediatrics 2012;129(3):e827-41.

5. World Health Organization. The optimal duration of exclusive breastfeeding: report of an expert consultation. http://www.who.int/nutrition/publications/optimal_duration_of_exc_bfeeding_report_eng.pdf. Accessed Nov 30, 2019.

6. Food and Agriculture Organization(FAO), International Fund for Agricultural Development(IFAD), United Nations Children's Fund(UNICEF), World Food Programme(WFP) and WHO. 2017. The State of Food Security and Nutrition in the world: In brief. http://fao.org/3/a17787e.pdf. Accessed Nov 30, 2019

7. World Health Organization Regional Office for Europe. WHO European Region has lowest global breastfeeding rates. http://www.euro.who.int/en/health-topics/Life-stages/maternal-and-newborn-health/news/news/2015/08/who-european-region-haslowest-global-breastfeeding-rates. Accessed Nov 30, 2019.

8. Theurich MA, Davanzo R, Busck-Rasmussen M, Díaz-Gómez N, Brennan C, Kylberg E, et al. Breastfeeding Rates and Programs in Europe: A survey 11 National Breastfeeding Committees and Representatives. J Pediatr Gastroenterol. Nutr 2019;68(3):400-7.

9. Centers for Disease Control and Prevention. National Center for Chronic Disease Prevention and Health Promotion, Division of Nutrition, Physical Activity, and Obesity. United Statess:Breastfeeding Report Card;2018. https://www.cdc.gov/breastfeeding/data/reportcard.htm Accessed Dec 31,2019

10. World Health Organization. WHO Global Nutrition Targets 2025: Breastfeeding Policy Brief. http://www.who.int/nutrition/publications/globaltargets2025_policybrief_breastfeeding. Accessed Nov 30, 2019

11. World Health Organization(WHO), United Nations Children's fund(UNICEF). Increasing commitment to breastfeeding through funding and improved policies and programmes: Global breastfeeding scorecard 2019. Accessed Nov 30, 2019.

12. Korean Ministry of Health and Welfare. National Health Plan 2020. 2016

13. Thulier D, Mercer J. Variables associated with breastfeeding duration. J Obstet Gynecol Neonatal Nurs 2009;38(3):259-68.

14. Langellier BA, Pia Chaparro M, Whaley SE. Social and institutional factors that affect breastfeeding duration among WIC participants in Los Angeles County, California. Matern Child Health J 2012;16:1887-95.

15. Laterra A, Ayoya MA, Beaulière J-M, Bienfait M, Pachón H. Infant and young child feeding in four departments in Haiti: mixed-method study on prevalence of recommended practices and related attitudes, beliefs, and other determinants. Rev Panam Salud Publica 2014;36(5):306-13.

16. Hure AJ, Powers JR, Chojenta CL, Byles JE, Loxton D. Poor adherence to national and international breastfeeding duration targets in an Australian longitudinal cohort. PLoS ONE.2013;8(1):e54409.

Page $11 / 13$ 
17. Kristiansen AL, Lande B, Øverby NC, Andersen LF. Factors associated with exclusive breast-feeding and breast-feeding in Norway. Public Health Nutr 2010;13(12):2087-96.

18. Hossain M, Islam A, Kamarul T, Hossain G. Exclusive breastfeeding practice during first six months of an infant's life in Bangladesh: a country based cross-sectional study. BMC pediatrics 2018;18(1):93.

19. Oakley LL, Henderson J, Redshaw M, Redshaw M, Quigley MA. The role of support and other factors in early breastfeeding cessation: an analysis of data from a maternity survey in England. BMC pregnancy childbirth 2014;14:88.

20. Banu B, Khanom K. Effect of education level of father and mother on perception of breastfeeding. J Enam Med Coll 2012;2(2): 67-73.

21. Li R, Darling N, Maurice E, Maurice E, Barker L, Grummer-Strawn LM. Breastfeeding rates in the United States by characteristics of the child, mother, or family: the 2002 National Immunization Survey. Pediatrics 2005;115(1):e31-7.

22. Lande B, Andersen LF, Veierød MB, Bærug A, Johansson L, Trygg KU, Bjørneboe GA. Breast-feeding at 12 months of age and dietary habits among breast-fed and non-breast-fed infants. Public Health Nutr 2004;7(4):495-503.

23. Jessri M, Farmer AP, Maximova K, Willows ND, Bell RC. Predictors of exclusive breastfeeding: observations from the Alberta pregnancy outcomes and nutrition(APrOn) study. BMC Pediatr 2013;13:77.

24. Al-Sahab B, Lanes A, Feldman M, Tamim H. Prevalence and predictors of 6-month exclusive breastfeeding among Canadian women: a national survey. BMC pediatr 2010;10:20.

25. Tang K, Wang H, Tan SH, Xin T, Qu X, Tang T, et al. Association between maternal education and breastfeeding practices in China: a population-based cross-sectional study. BMJ Open 2019;9(8):e028485.

26. Hajian-Tilaki KO. Factors associated with the pattern of breastfeeding in the north of Iran. Ann Hum Biol 2005;32(6):702-13.

27. Acharya P, Khanal V. The effect of mother's educational status on early initiation of breastfeeding: further analysis of three consecutive Nepal Demographic and Health Surveys. BMC Public Health 2015;15:1069.

28. Flacking R, Dykes F, Ewald U. The influence of father's socioeconomic status and paternity leave on breastfeeding duration: A populationbased cohort study. Scand J Public Health 2010;38:337-43.

29. Yalc, In SS, Yalc, In S, Kurtulus,-Yi git E. Determinants of continued breastfeeding beyond 12 months in Turkey: secondary data analysis of the Demographic and Health Survey. Turk J Pediatr 2014;56(6):581-91.

30. Senarath U, Siriwardena I, Godakandage SS, Jayawickrama H, Fernando DN, Dibley MJ. Determinants of breastfeeding practices: an analysis of the Sri Lanka Demographic and Health Survey 2006-2007. Matern Child Nutr 2012;8(3):315-29.

31. Wallby T, Hjern A. Region of birth, income and breastfeeding in a Swedish county. Acta Paediatr 2009;98(11):1799-804.

\section{Figures}


Participants $(\mathrm{n}=31,098)$ from the Korean National Health and Nutrition Examination Survey (KNHANES), $2013 \sim 2017$

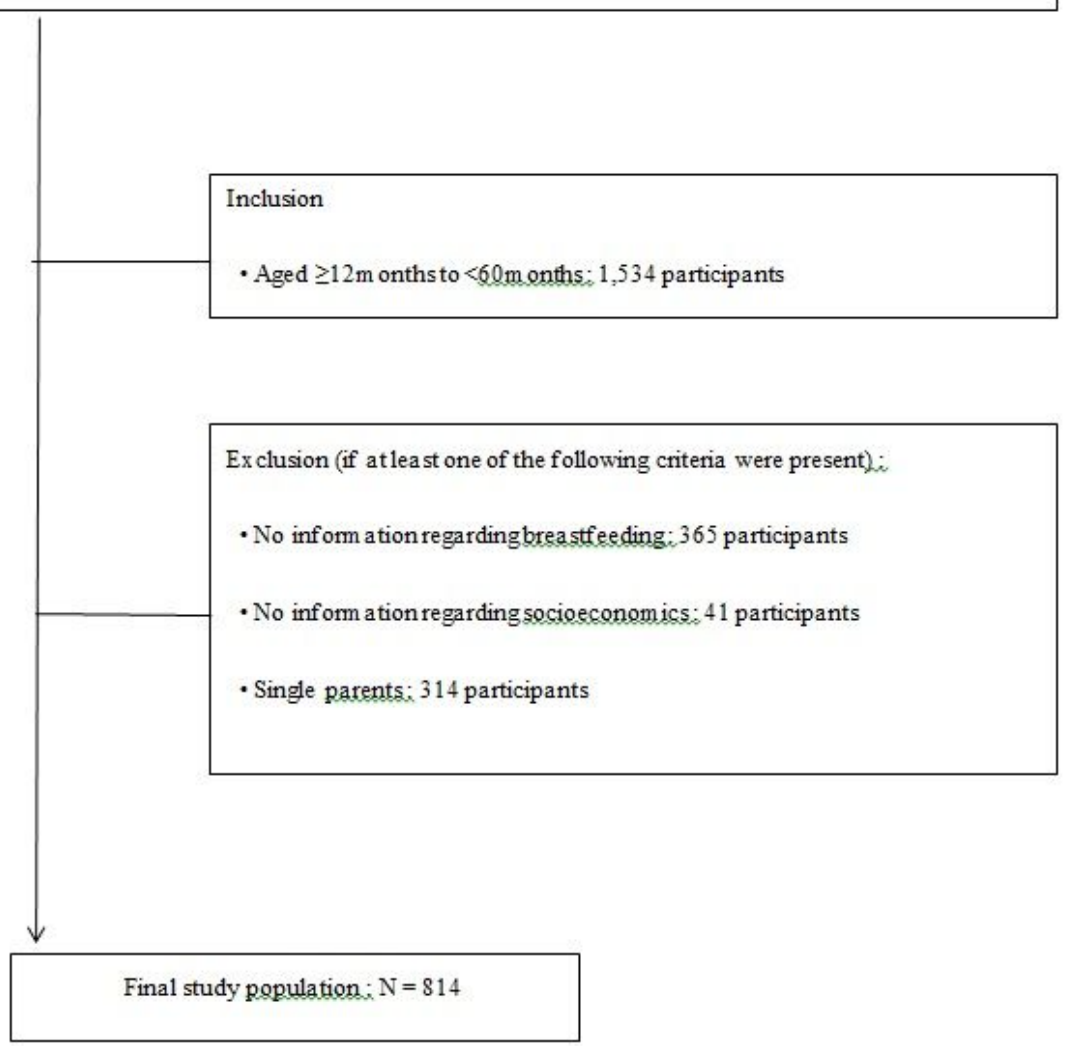

\section{Figure 1}

Flow chart of the sample selection process of the study population 